Polymer Journal, Vol. 38, No. 7, pp. 651-658 (2006)

(C) 2006 The Society of Polymer Science, Japan

\title{
Polymerization of Aniline through Simultaneous Chemical and Electrochemical Routes
}

\author{
Ali EFTEKHARI ${ }^{\dagger}$ and Parvaneh JAFARKHANI \\ Laboratory of Electrochemistry, Materials and Energy Research Center, P.O. Box 14155-4777, Tehran, Iran
}

(Received December 1, 2005; Accepted February 21, 2006; Published May 29, 2006)

\begin{abstract}
Simultaneous chemical and electrochemical polymerization of aniline was investigated to explore the competition between two polymerization routes. It was found that initial chemical polymerization may significantly affect the electrochemical polymerization; thus, it is possible to control the polymer morphology. By performing the electropolymerization with slow scans, the initial chemical polymerization results in the formation of a nanostructured backbone, which will also affect subsequent electropolymerization (even in the absence of chemical polymerization). By this trick, it is possible to prepare highly porous and uniform nanostructured polyaniline film adherently attached to the substrate surface. In fact, chemically synthesized polyaniline nano-particles acts as growth sites for electrochemical polymerization, and in appropriate condition, numerous sites are formed instead of their continuous growth. [doi:10.1295/polymj.PJ2005181]

KEY WORDS Polyaniline / Electropolymerization / Chemical Polymerization / Conductive Polymers / Nanostructured Polymer / Nanostructure /
\end{abstract}

Conductive polymers are a famous class of polymer materials and were subject of many researches during the past decades, since they have been discovered just by $1977 .{ }^{1}$ This considerable attention can be attributed to their invaluable advantages for various applications. There are two different methods for the preparation of conductive polymers. The first one is classical chemical polymerization, and this method is generally applicable for all polymers, and the other alternative method is electrochemical polymerization due to pioneering works of Diaz, ${ }^{2-4}$ which is an exclusive route for the synthesis of conductive polymers because of their conductivity. In the chemical polymerization, an oxidant is responsible for the polymerization process, and in electropolymerization this is due to the electrical charge. Since the latter one results in the formation of a film of the conductive polymer onto substrate electrodes, it is of particular interest for advanced technologies employing thin films. Although conductive polymers synthesized chemically and electrochemically have been compared in the literature, ${ }^{5-11}$ less attention has been paid to an important issue to investigate simultaneous polymerization via chemical and electrochemical routes. In the present work, we aim to examine this issue in a widely known system.

Polyaniline as a classical polymer is a prototype of conductive polymers, which was among the first polymers synthesized electrochemically. ${ }^{4}$ There is a considerable attention to polyaniline and has been widely investigated for electronic and optical applications due to its good environmental stability and tunable electrical and optical properties. ${ }^{12,13}$ Polymerization of the monomer aniline, can be achieved either chemically ${ }^{14-25}$ or electrochemically. ${ }^{26-36}$ In fact, both polymerization routes have been widely investigated in the literature. In the chemical synthesis of polyaniline, various oxidants including ammonium persulfate, potassium bichromate, potassium iodate, potassium permanganate, hydrogen peroxide, etc have been used for the oxidative polymerization of aniline, but the most frequent exploited oxidant is ammonium persulfate. For the electrochemical polymerization, different electrochemical techniques such as galvanostatic, potentiostatic, and potentiodynamic conditions have been employed. Among these techniques, potentiodynamic polymerization have some valuable advantages for the deposition of an ideal polymer film, and particularly it is able to monitor the polymer growth in the course of cyclic polymerization at different stages of the polymer formation on substrate surface. Thus, we attempt to examine the competition of chemical and electrochemical polymerization for this common case, viz. potentiodynamic polymerization of aniline onto Pt substrate and chemical polymerization of this monomer by means of ammonium persulfate oxidant.

\section{EXPERIMENTAL}

Deposition of polyaniline films was performed in an acidic solution of $0.1 \mathrm{M} \mathrm{H}_{2} \mathrm{SO}_{4}$ containing $30 \mathrm{mM}$ aniline in the presence of $30 \mathrm{mM}$ ammonium persulfate. The experiments were made in a one-compartment cell using a standard three-electrode electrochemical cell arrangement. The potential was referenced to a

${ }^{\dagger}$ To whom correspondence should be addressed (Tel: +98-261-621-0009, Fax: +98-261-620-1888, E-mail: eftekhari@merc.ac.ir). 
saturated calomel electrode (SCE), the counter electrode was a platinum sheet. The potentiodynamic polymerization of aniline was performed by cycling the potential between -0.2 and $1.0 \mathrm{~V}$ with various scan rates.

It is of particular importance to provide an opportunity for exactly simultaneous chemical and electrochemical polymerization. The chemical polymerization just starts by adding the oxidant to the polymerization bath; whereas, starting the electrochemical experiment takes a time. Thus, we should shorten the individualistic chemical polymerization before performing the electrochemical experiment. For this purpose, the electrochemical cell was set up, and a solution of the oxidant was poured (the concentrations quoted above correspond to the final solution) to the cell. Then, the cell was just stirred for $2 \mathrm{~s}$ to assure complete mixedness of the reactant, following by a rest time of $5 \mathrm{~s}$ to obtain a stationary fluid; then the electrochemical experiment was immediately performed. In this manner, the individual polymerization via only chemical route is restricted to lesser than $10 \mathrm{~s}$.

All electrochemical experiments were performed using a Princeton Applied Research potentiostat/galvanostat model 173 (PAR 173) equipped with a model 175 universal programmer in conjunction with CorrView software. SEM images were recorded using a Philips XL 30 scanning electron microscope.

\section{RESULTS AND DISCUSSION}

Figure 1 compares electrochemical polymerization of aniline under conventional conditions, but in the presence and absence of ammonium persulfate as an oxidative agent to induce chemical polymerization simultaneously. Figure 1a manifestly shows the absence of common strong oxidation peak appearing at high potentials during the first cycle (c.f. Figure 1b), which is attributed to the water and monomer oxidation by bare Pt. Having a closer and more careful gaze at what happening within the cell, one would come to this conclusion that chemically synthesized polyaniline is adsorbed on the Pt surface, which makes the metallic surface of electrode disable to electrocatalyze the water.

Another consequence of this strong oxidation process occurring at high potential is to oxidize the substrate surface, as it has been described that a certain charged should be passed through the cell before the occurrence of electropolymerization. ${ }^{37,38}$ In other words, electropolymerization on the substrate will not be occurred unless the substrate surface is sufficiently oxidized. Of course, this oxidation is not dominantly due to the electrical charge, as the electrolyte medium plays an important role. This is the reason that in the presence of appropriate medium, a lesser


Figure 1. Potentiodynamic polymerization of aniline onto Pt substrate. The electrolyte solution was $30 \mathrm{mM}$ aniline in $0.1 \mathrm{M} \mathrm{H}_{2} \mathrm{SO}_{4}$ as supporting electrolyte in the (a) presence and (b) absence of ammonium persulfate. The scan rate was $50 \mathrm{mV} /$ $\mathrm{s}$ for 50 successive cycles.

charge is required for this process. ${ }^{38}$ Therefore, ammonium persulfate as a strong oxidative agent could assist the initial oxidation of the Pt substrate electrode, and consequently, the strong oxidation peak at high potentials is absent for such chemically oxidized $\mathrm{Pt}$ substrate.

The existence of ammonium persulfate and possible chemical polymerization strongly affect the polyaniline morphology. According to the SEM images (Figure 2), two different types of morphology can be detected in the sample: macro-fibers and micro-particles. Of course, these are morphological structure of the polyaniline film adherently attached to the Pt substrate surface. Interestingly, both of these morphological structures are in the same scale, and this suggests that the overall mechanism of the polymer growth is the same but the difference is due to the growth direction. In other words, these are not related to different polymerization processes whether chemically or electrochemically, but both structures have been formed as a result of mixed-processes. Indeed, since it is difficult to assume that incorporation of the chemically synthesized polyaniline within the matrix of the poly- 
(a)

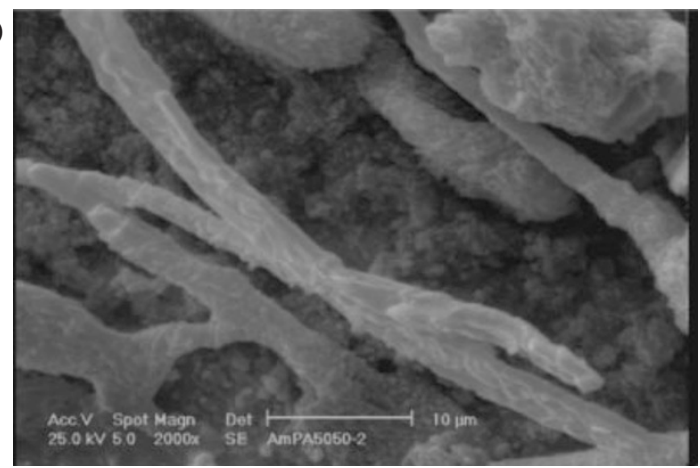

(b)

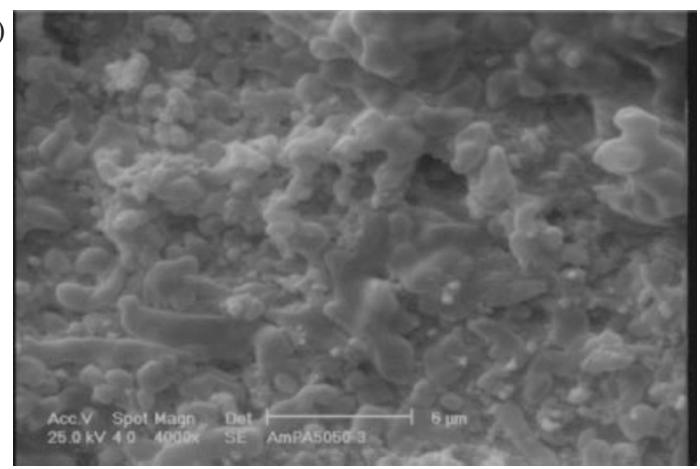

Figure 2. SEM images of the polyaniline film electrochemically grown on $\mathrm{Pt}$ in the presence of ammonium persulfate.

aniline film formed electrochemically, one may attribute this phenomenon (i.e., formation of different structures) to local inhomogeneities.

Since simultaneous chemical and electrochemical polymerization is indeed accompanied by a competition between two different routes, it is useful to vary the rate of one process while keeping the other constant. It is the advantage of electrochemical processes, which can be easily controlled by changing the electrical charge. Whereas, controlling the chemical poly- merization in this competition is difficult as the electrochemical polymerization is also affected. In potentiodynamic experiments, it is possible to control the polymerization process by varying the potential scan rate, as the polymerization is periodic in accordance with the applied potential. Thus, at higher scan rates (e.g., scan rate $200 \mathrm{mV} / \mathrm{s}$ as illustrated in Figure 3 ), the chemically synthesized polyaniline has lesser time to be incorporated into the electrochemical formed polyaniline matrix. For obtaining the opportunity of a comparative study, the electrochemical polymerization with scan rate $200 \mathrm{mV} / \mathrm{s}$ was performed during 150 successive cycles (Figure 3), as the charge passed through the electrochemical cell which is indicative of the amount of polymer deposited onto the substrate surface, is approximately the same as the case reported in Figure 1a.

With approximately the same polymerization time and the amount of polymer synthesized, it is obvious that cyclic voltammetric behaviors for corresponding electrochemical polymerizations are significantly different. Although the last cycles in both cases are similar, but initial successive cycles are completely different. For the sake of clarity, the first 100 cycles were omitted in Figure 3, and from the internal shape appeared, one can understand the difference in the initial electrochemical polymerization. This indicates that a certain time is required for the completeness of chemical polymerization to participate in the competition. It should be taken into account that faster electrochemical polymerization does not exclude the role of chemical polymerization in the competition, as the initial electrochemical polymerization in Figure 3 is not similar to the conventional case in the absence of ammonium persulfate; however, this effect is not in favor of

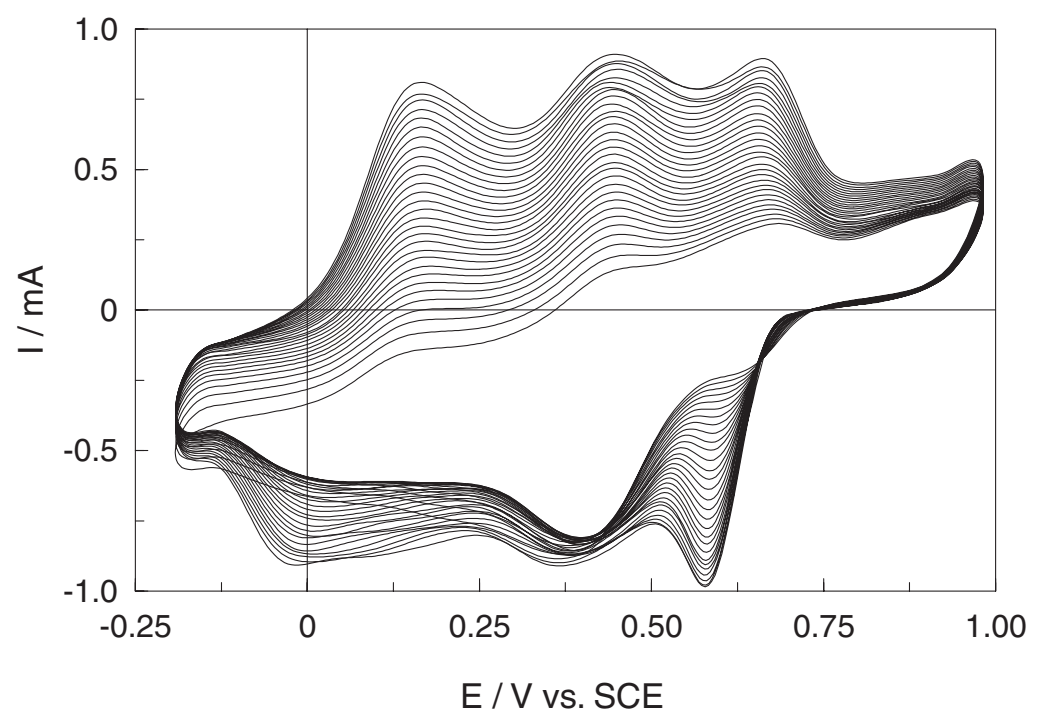

Figure 3. Cyclic voltammetric behavior of the aniline electropolymerization with scan rate $200 \mathrm{mV} / \mathrm{s}$ for 150 successive cycles. The 100 first cycles were omitted and the figure is representative of cycles $100-150$. 
ideal electropolymerization.

The above mentioned irregularities in the polyaniline morphological structure of the polyaniline film is observable (Figure 4) as well as the case of 50 $\mathrm{mV} / \mathrm{s}$ reported above (Figure 2). This provides a strong evidence for the fact that this is an essential result of simultaneous chemical and electrochemical polymerization at high scan rates, as local inhomogeneities are inevitable.
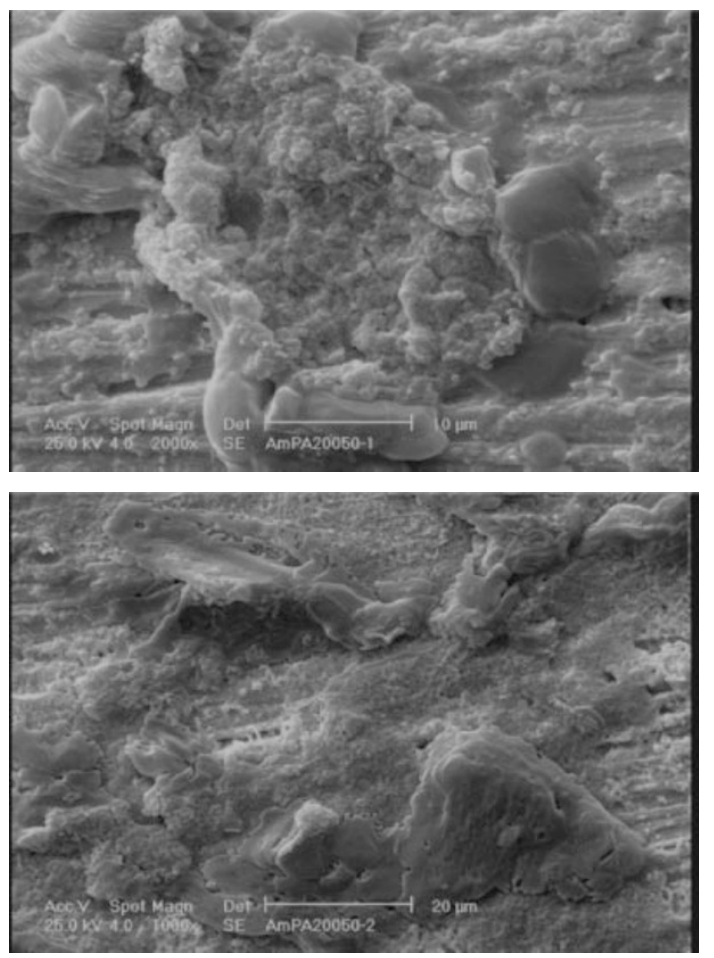

Figure 4. Morphological structure of the polyaniline film prepared under the experimental condition specified in Figure 3.
According to the important role of the electrochemical polymerization rate in this competition, lowering the scan rate is worth considering. Figure 5 shows the polyaniline synthesized under slow potential cycling with scan rate of $5 \mathrm{mV} / \mathrm{s}$ for only 10 successive cycles. The experiment time for the electrochemical polymerization is approximately similar to those reported above. The charge passed through the electrochemical cell is also comparable with the previous cases. However, a major difference is appeared in the film morphology (Figure 6). In the latter case, the morphological structure is uniform with nanostructure. In other words, the system is sufficiently stayed in a given potential as the rate of electrochemical polymerization at a specified step is comparable with that of chemical polymerization; thus, initial polyaniline nano-particles formed chemically will be appropriate sites for subsequent polymer growth via electrochemical route. It has been discussed that different growth sites on the substrate electrode may

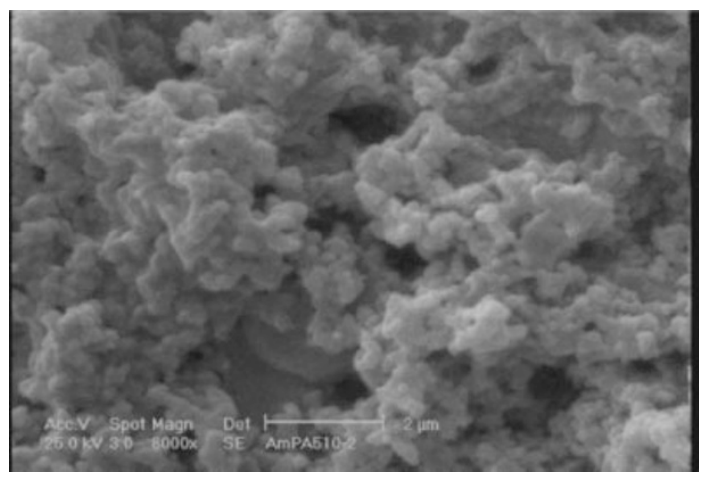

Figure 6. SEM images of the sample prepared with slow electropolymerization (scan rate $5 \mathrm{mV} / \mathrm{s}$ ).

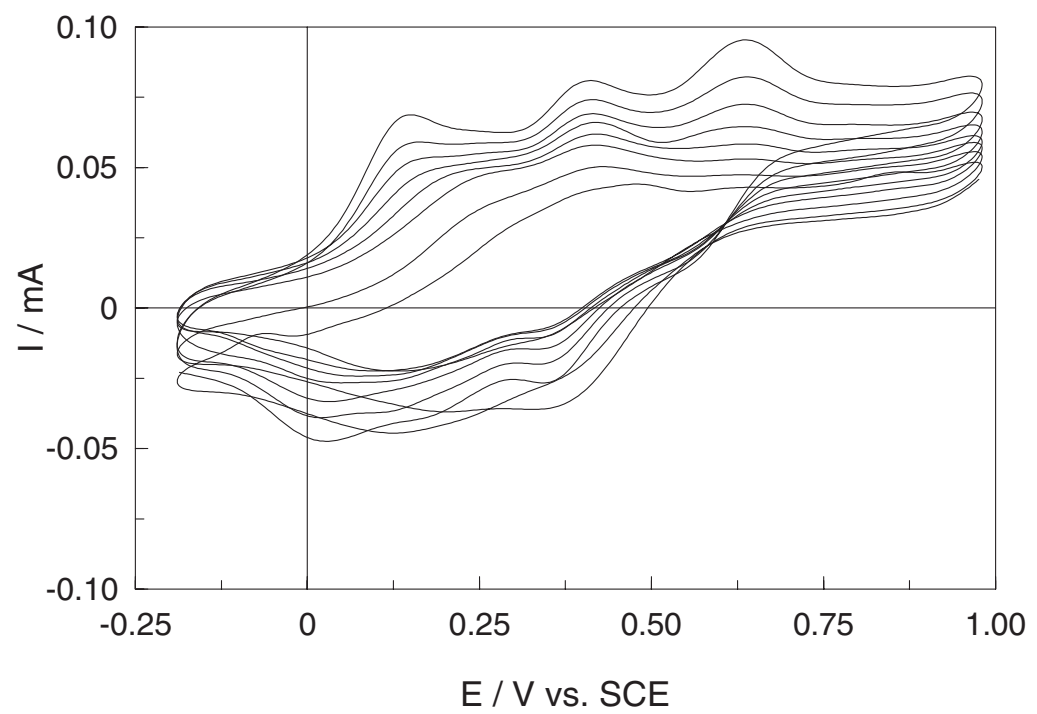

Figure 5. Cyclic voltammetric behaviors corresponding to the aniline polymerization with slow electrochemical polymerizations recorded with scan rates: $5 \mathrm{mV} / \mathrm{s}$ for 10 cycles. 
result in the formation of different polymerization pathway and consequently significantly different morphology. ${ }^{39}$ In general, chemical inhomogeneities of substrate surface strongly affect electrochemical systems. ${ }^{40}$ In fast electrochemical polymerization, the same mechanism is followed, but there is not sufficient time for the generation of new growth sites, and the electrochemically synthesized polyaniline tends to form on available growth sites in the course of a fast electrochemical polymerization.

According to the usefulness of slow electrochemical polymerization for the preparation of uniform nanostructured polyaniline film, it is enticing to examine its applicability out of the competition. During long experiment times (higher numbers of potential cycles), the chemical polymerization is negligible and the electropolymerization is dominant. For instance, for 50 successive cycles with the scan rate of $1 \mathrm{mV} / \mathrm{s}$ the experiment time is about 2,000 $\mathrm{min}$. The effective chemical polymerization in the experimental conditions under investigation is about $30 \mathrm{~min}$, as it was examined through chemical polymerization out of the electrochemical cell. Thus, it can be assumed that the chemical polymerization and its corresponding competition with the electrochemical polymerization is only noticeable during first cycles, and for subsequent cycles, it is just electrochemical polymerization, but in a situation which is highly affected with the initial competition.

Figure 7 shows the potentiodynamic electropolymerization of aniline under slow rate in the presence and absence of ammonium persulfate. The charge passed through the electrochemical cell in both cases is approximately the same, indicating that the amount of polyaniline deposited onto the electrode surface is independent of the chemical polymerization. Since the chemical polymerization only occurs in a small part of the polymerization process, this difference is negligible and the amount of the polyaniline film deposited is mainly due to the electrochemical process. However, the gradual increase of the peak currents is monotonic for the conventional case (Figure 7b), but the charge under peaks is higher during the first cycles in the presence of ammonium persulfate which is obviously related to the role of chemical polymerization.

Although the chemical polymerization was absent during the formation of lateral structure of the polyaniline film, a significant difference in the film morphologies is observable (Figure 8). In fact, the initial chemical polymerization results in the formation of a different backbone leading to subsequent growth of nanostructured polyaniline, as this feature is not applicable in the absence of the initial chemical polymerization. In other words, by introducing an initial
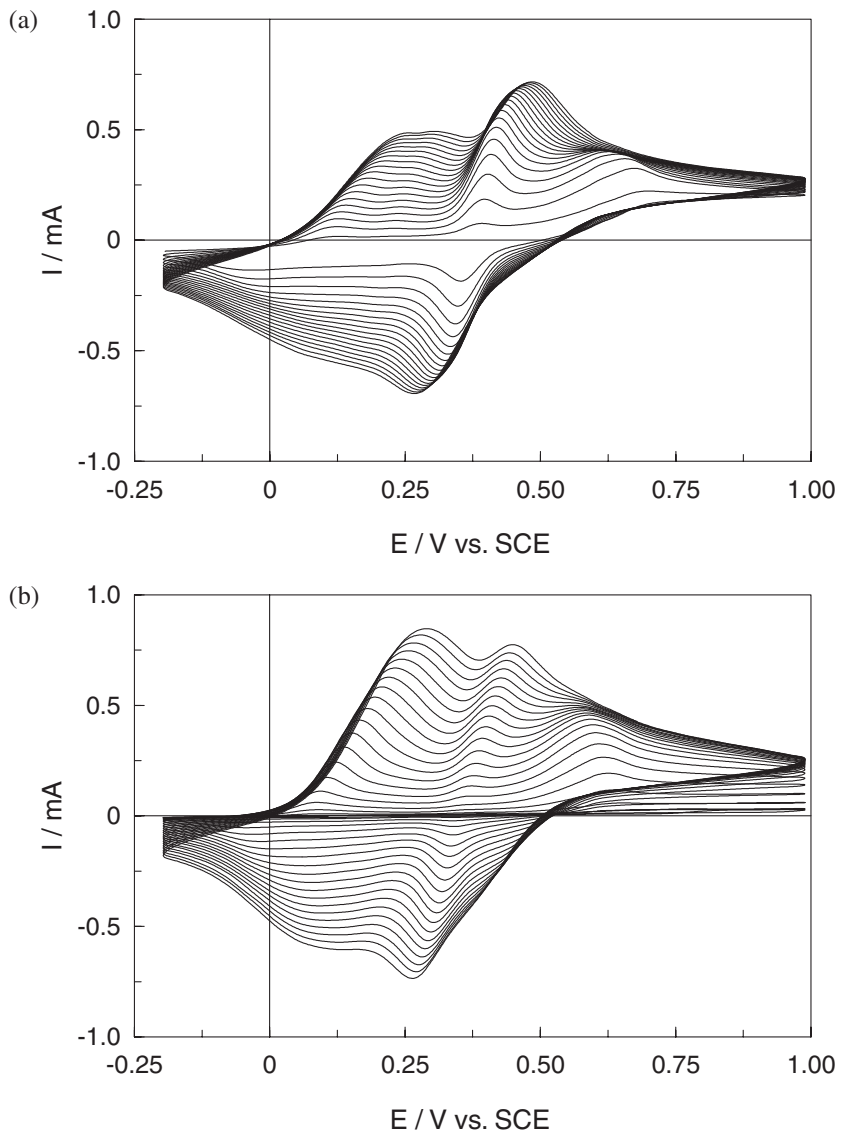

Figure 7. Electropolymerization of aniline under slow scan (scan rate $1 \mathrm{mV} / \mathrm{s}$ ) in the (a) presence and (b) absence of ammonium persulfate.

chemical polymerization to an electropolymerization system, it is possible to control the dynamical pathway of the system leading to the formation of favorable morphological structure.

According to the role of chemically synthesized polyaniline on subsequent electrochemical polymerization, one may think about similar condition prepared by injection of polyaniline ex situ synthesized chemically into the electrochemical cell. Comparison of the potentiodynamic growth of polyaniline in this case (Figure 9) with that obtained in the presence of in situ formed polyaniline (c.f. Figure 1a) indicates significant differences. Since the amount of chemically synthesized polyaniline is higher thus a strong electrochemical behavior is observable for the first cycle in Figure 9. However, in spite of higher amount of chemically synthesized polyaniline, which is available for adsorption to the electrode surface, since the adsorption is not occurred during in situ formation of the polyaniline, it is thought that this adsorbed layer is highly porous and instable. On the other hand, oxidation peak (but not strong) associated with the electro-oxidation of water and monomer by metallic Pt electrode is observable during the first cycles. 
(a)

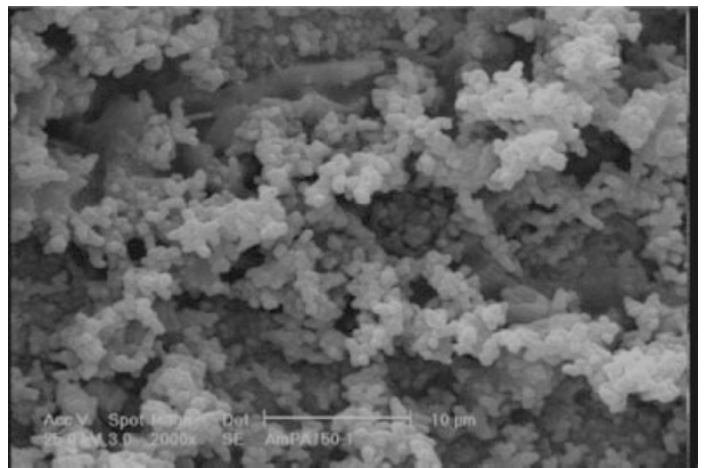

(b)

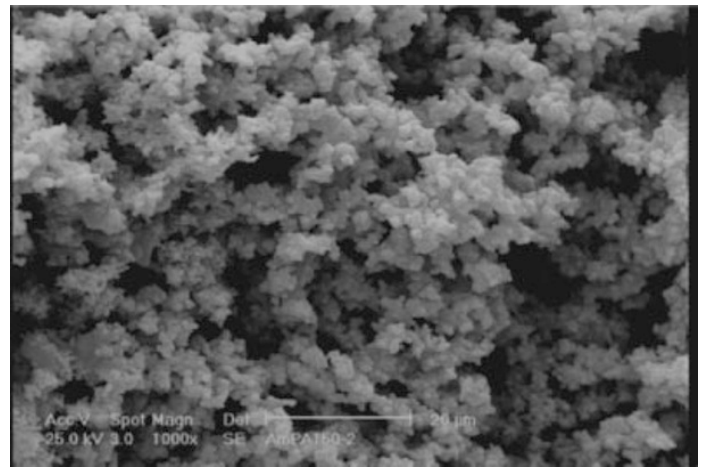

(c)

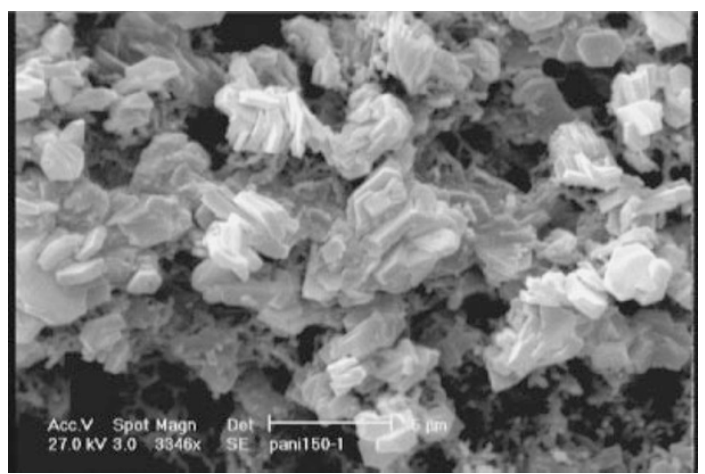

Figure 8. Morphological structures of the polyanilines films prepared by slow electropolymerization in the (a), (b) presence and (c) absence of the oxidant.
Similarly, a significant difference in the morphological structure is observable (comparing Figure 10 with Figure 2a). Nevertheless, the morphological structure of the polyaniline film prepared in the presence of dispersed polyaniline is of particular interest, as it has a uniform structure like that prepared under slow electropolymerization (Figure 8). This provides a strong evidence for the fact that existence of chemically synthesized polyaniline is responsible for the formation of such porous nanostructure. Of course, it should be emphasized that the polyaniline film prepared by initial dispersion of chemically synthesized polyaniline has lesser stability in comparison with that prepared by in situ chemical polymerization. This failure is attributed to weak attachment of a huge amount of polyaniline particles dispersed with the cell before the electropolymerization process.

According to the latter results, it can be concluded that the chemically synthesized polyaniline is responsible for phenomena reported above. However, one may think that the existence of ammonium persulfate

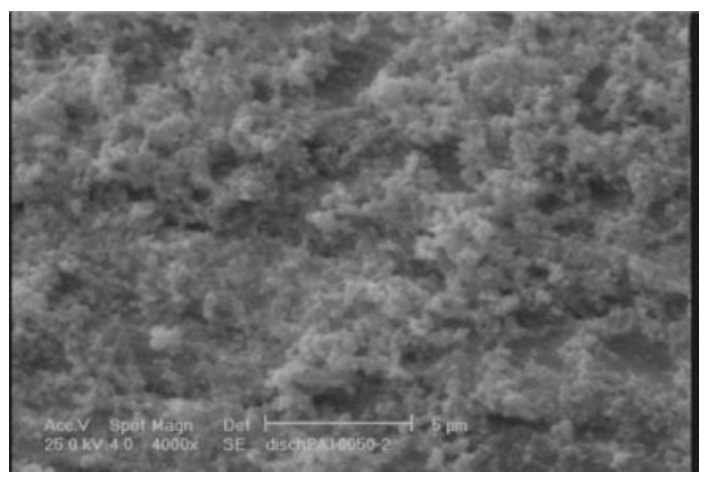

Figure 10. Morphology of the polyaniline film prepared in the presence of dispersed polyaniline particles.

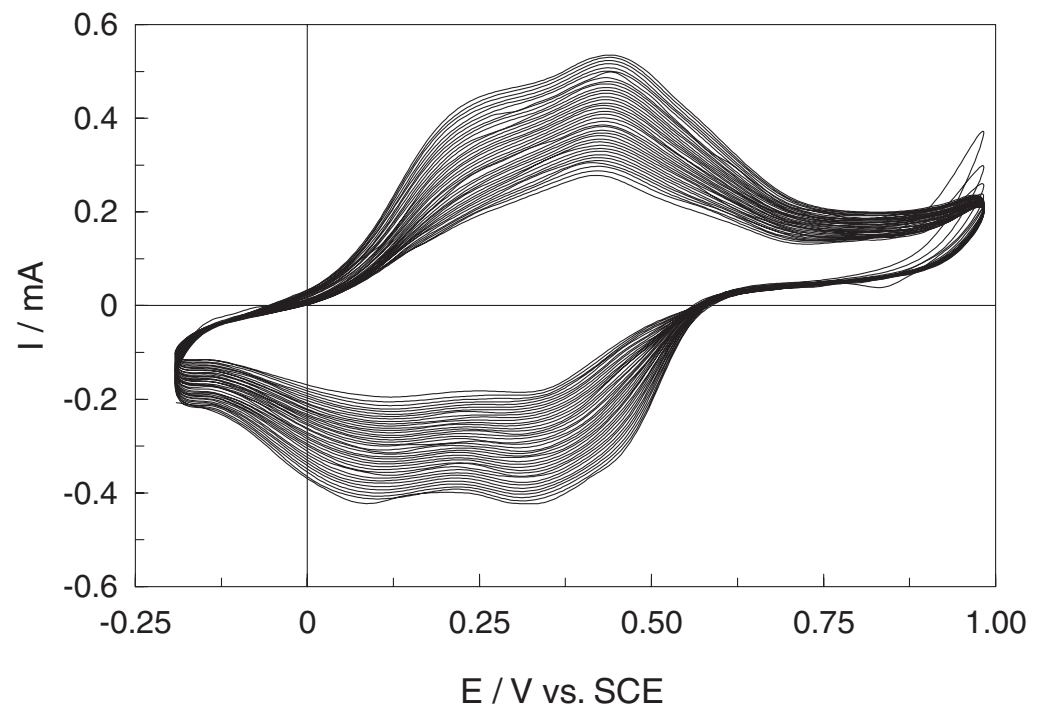

Figure 9. Electrochemical polymerization of aniline from a cell containing ex situ chemically synthesized polyaniline. Scan rate $100 \mathrm{mV} / \mathrm{s}$. 
(a)

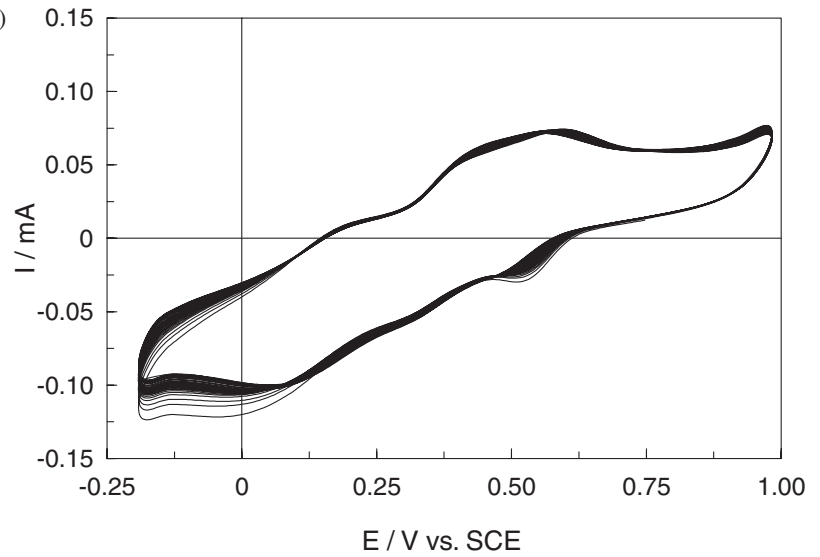

(b)

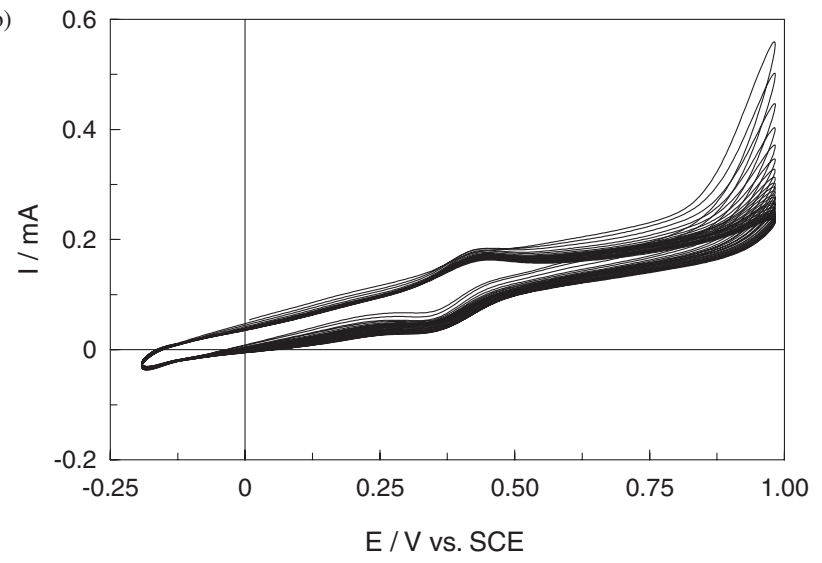

Figure 11. Electrochemical polymerization of aniline from electrolyte solutions prepared by filtering the chemically synthesized polyaniline after (a) $1 \mathrm{~h}$, and (b) 1 day. The initial solution was $30 \mathrm{mM}$ aniline in $0.1 \mathrm{M} \mathrm{H}_{2} \mathrm{SO}_{4}$ as $30 \mathrm{mM}$ ammonium persulfate was also added as oxidative agent for chemical polymerization. The CVs were recorded with scan rate $100 \mathrm{mV} / \mathrm{s}$.

may affect the electrochemical polymerization as the polyaniline is precipitated in the bottom of the cell. To examine this feature, the cell was left for a certain time and then filtered. By this action, the electrolyte solution contains all reactant but without chemically synthesized polyaniline. As can be seen in Figure 11a, electrochemical polymerization is negligible, but the electrochemical activity of the first cycle is indicative of adsorption of significant amount of polyaniline. In fact, these are just the polyaniline synthesized chemically after $1 \mathrm{~h}$. As expected, no oxidation peak is observable during the first cycle as the Pt electrode is initially coated with in situ formed polyaniline. However, note that the charge is very low in comparison with the cases reported above.

By filtering the electrolyte solution after 1 day, any possible chance for in situ chemical formation of polyaniline is missed out, and there will be no chemically synthesized polyaniline to be adsorbed on the electrode surface. Thus, the bare Pt is available for the occurrence of strong oxidation process at high potentials (Figure 11b). Under these conditions, the mono- mer has been consumed and sufficient aniline is not available for electrochemical polymerization. However, we witnessed that even in the presence of similar chemical polymerization, the electrochemical polymerization was actively performed after more than 1 day (Figure 6a). This leads us to an interesting conclusion that in the simultaneous chemical and electrochemical polymerization, there is a great chance to consume larger amounts of the monomer from the reactor. In other words, there is a concentration threshold for the occurrence of electrochemical polymerization, and this threshold is significantly lower for simultaneous chemical and electrochemical polymerization.

\section{CONCLUSION}

Simultaneous chemical and electrochemical polymerization of aniline as a prototype of conductive polymers was investigated. The results obtained are of both fundamental and applied interest. In the competition between chemical and electrochemical polymerization, it is possible to control the polymer growth pathway and consequently morphological structure of the polymer. Thus, this provides an opportunity to investigate and compare these two polymerization routes in situ. On the other hand, preparation of conductive polymers with desirable morphology is possible. The system under investigation was a typical case with only one controllable parameter; whereas, investigation of other systems by varying different controllable parameters will surely lead to interesting results. For various reasons, simultaneous chemical and electrochemical polymerization is more favorable from commercial point of view, as the polymerization process proceeds with lesser concentration of the monomer.

\section{REFERENCES}

1. H. Shirakawa, E. J. Louis, A. G. MacDiarmid, C. K. Chiang, and A. J. Heeger, J. Chem. Soc., Chem. Commun., 578 (1977).

2. A. F. Diaz, K. K. Kanazawa, and G. P. Gardini, J. Chem. Soc., Chem. Commun., 635 (1979).

3. A. F. Diaz and J. L. Castillo, J. Chem. Soc., Chem. Commun., 397 (1980).

4. A. F. Diaz and J. A. Logan, J. Electroanal. Chem., 11, 111 (1980).

5. Y. Wei, R. Hariharan, and S. A. Patel, Macromolecules, 23, 758 (1990).

6. E. Sezer, B. Ustamehmetoglu, and A. Sezai Sarac, Synth. Met., 107, 7 (1999).

7. L. H. Shi, J. Roncali, and F. Garnier, Macromolecules, 25, 6425 (1992).

8. S. Palaniappan, Eur. Polym. J., 37, 975 (2001). 
9. H. Muller and B. Divisia-Blohorn, J. Chem. Phys., 95, 1184 (1998).

10. H. L. Wang, R. M. O'Malley, and J. E. Fernandez, Macromolecules, 27, 893 (1994).

11. S. Patra and N. Munichandraiah, Synth. Met., 150, 285 (2005).

12. J. C. Chiang and A. G. MacDiarmid, Synth. Met., 13, 193 (1986).

13. Y. N. Xia, J. M. Wiesinger, A. G. MacDiarmid, and A. J. Epstein, Chem. Mater., 7, 443 (1995).

14. Z. X. Wei, Z. M. Zhang, and M. X. Wan, Langmuir, 18, 917 (2002).

15. Y. Fong and J. B. Schlenoff, Polymer, 36, 639 (1995).

16. H. J. Qiu and M. X. Wan, J. Polym. Sci., Part A: Polym. Chem., 39, 3485 (2001).

17. J. X. Huang, S. Virji, B. H. Weiller, and R. B. Kaner, J. Am. Chem. Soc., 125, 314 (2003).

18. J. X. Huang and R. B. Kaner, J. Am. Chem. Soc., 126, 851 (2004).

19. X. Y. Zhang, W. J. Goux, and S. K. Manohar, J. Am. Chem. Soc., 126, 4502 (2004)

20. E. M. Genies, C. Tsintavis, and A. A. Syed, Mol. Cryst. Liq. Cryst., 121, 181 (1985).

21. Z. Sun, Y. Geng, J. Li, X. Jing, and F. Wang, Synth. Met., 84, 99 (1997).

22. R. Hirase, T. Shikata, and M. Shirai, Synth. Met., 146, 73 (2004).

23. A. Pron, F. Genoud, C. Menardo, and M. Nechtschein, Synth. Met., 24, 193 (1988).
24. Y. Cao, A. Andreatta, A. J. Heeger, and P. Smith, Synth. Met., 30, 2305 (1989).

25. A. Falcou, A. Duchene, P. Hourquebie, D. Marsacq, and A. Balland-Longeau, Synth. Met., 149, 115 (2005).

26. E. M. Genies and C. Tsintavis, J. Electroanal. Chem., 195, 109 (1985).

27. A. Watanabe, K. Mori, A. Iwabuchi, Y. Iwasaki, Y. Nakamura, and O. Ito, Macromolecules, 22, 3521 (1989).

28. Y. Yang and S. Mu, J. Electroanal. Chem., 432, 71 (1997).

29. L. H. C. Mattoso, R. M. Faria, L. O. S. Bulhoes, and A. G. MacDiarmid, Polymer, 35, 5104 (1994).

30. K. R. Prasad and N. Munichandraiah, Synth. Met., 123, 459 (2001).

31. L. Sun, H. C. Zhang, C. M. Jiang, Q. R. Li, and R. K. Bai, Polym. J., 37, 350 (2005).

32. K. Endo and H.-B. Bu, Polym. J., 33, 156 (2002).

33. B. M. Tidswell and S. C. Gilchrist, Polymer, 21, 805 (1980).

34. J. M. Ortega, S. Menolasina, O. P. de Marquez, and J. Marques, Polymer, 27, 1304 (1986).

35. K. Tanaka, T. Shichiri, S. Wang, and T. Yamabe, Synth. Met., 24, 203 (1988).

36. K. J. Wynne and G. B. Street, Macromolecules, 18, 2361 (1985).

37. A. Eftekhari, Synth. Met., 125, 295 (2001).

38. A. Eftekhari, Synth. Met., 145, 211 (2004).

39. A. Eftekhari, M. Kazemzad, and M. Keyanpour-Rad, Polym. J., 38, 329 (2006).

40. A. Eftekhari, M. Kazemzad, and M. Keyanpour-Rad, Appl. Surf. Sci., 239, 311 (2005). 